\title{
BIM APPROACH FOR DECISION SUPPORT: CASE STUDY FASTENING SYSTEMS IN FACTORY ADAPTATION PLANNING
}

\author{
Lisa Theresa Lenz, Mike Gralla, Marvin Hoepfner, Panagiotis Spyridis and Kai Christian Weist \\ Technical University, Dortmund, GER
}

\begin{abstract}
Increasing and changing product requirements demand a permanent readiness for efficient factory adaption. Considering necessary construction adaptions as well as conventional construction planning processes in the context of the factory adaptation process, standard planning methods are unable to support in a fast and efficient way. By application of the BIM method a Building Information Model, which contains all the needed information in one database is generated. BIM is a method for achieving targets, such as selecting the right type of construction technology or building material to evaluate the adaptation measure. The challenges by putting all information in one model are dealing with the amounts of data, identifying data quality and determining the current use case which should be examined. In this publication, the necessary data base is identified and implemented into a Building Information Model to investigate the right fastening system for an Industry 4.0 case study. The use case describes an integration of a robot into a factory in the life cycle phase operation to evaluate, which fastening system is most suitable as a part of taking adaption intelligence of a building to a higher level.
\end{abstract}

\section{Introduction}

A key result of the digitalization of construction industry are feature-rich Building Information Models that include semantically annotated parts for a growing number of building types, including factories (Delbruegger et al., 2017). BIM-Models have the potential to be used for a wide variety of tasks around the lifecycle of a building and handle them more efficiently. Nevertheless, there are a lot of challenges by using the BIM-method. The essence of the challenges is located in the variety of different file formats that are not or only partially related to each other (Gralla et al., 2018). However, a true potential lies in the data analysis and by getting the data of different systems like building parts, as the floor-slab, building materials, as a fastening system and an Industry 4.0 use case, as using a robot in a factory together. For this, all relevant data are analysed and put together in one BIM-Model. In addition, different rules are defined and software-based checked in a modelchecker in order to be able to identify the interfaces and dependencies, to finally find an approach for semi- automated BIM-based decision support for choosing the right fastening system. The case study introduced here is a BIM approach for semi-automatic decision support for factories that combines data of different building categories, as building parts and building materials with data of an Industry 4.0 use case in a Building Information Model and investigates interfaces and dependencies.

\section{Utilized Technologies}

This section presents a couple of basic technologies and the different types of data that are used in our case study.

\section{Building Information Modeling}

Building Information Modeling (BIM) is a method in the construction industry that includes the generation and management of digital representations of physical and functional characteristics of a building (Egger et al., 2013).

Building information models represent a database that provides a reliable knowledge base for decisions throughout a building's life cycle - from initial planning to demolition. BIM also offers the ability to optimize processes related to the life cycle of a building. The basis for the integration of different processes is a consistent virtual building model that is updated through the different phases of planning and building (Delbruegger et al., 2017).

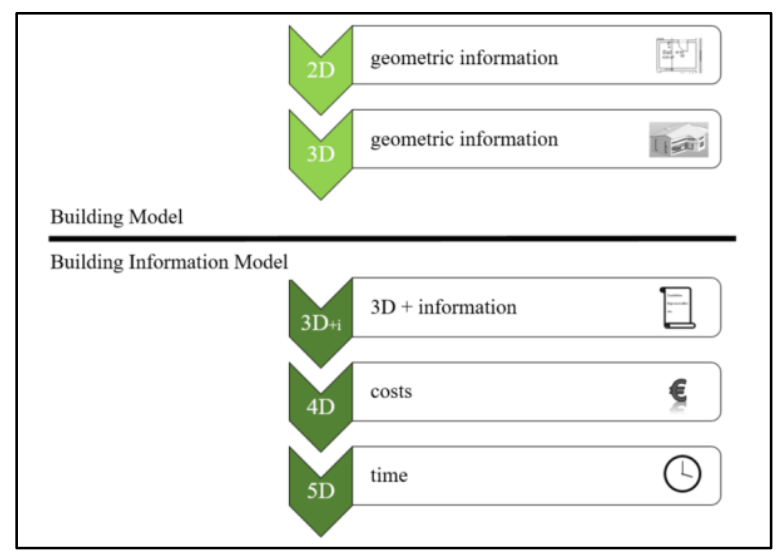

Figure 1: Building Information Modeling vs. conventional planning (Gralla et al., 2017)

As figure 1 illustrates the BIM method is separated from conventional planning methods at the point from planning in three dimensions by using just geometric 
data to three dimensions combined with other information e.g. data like quality information or maximum loads. At this stage it turns from a building model to a building information model, where information about time and costs are associated into the fourth and fifth dimension.

\section{Data analysis of floor slab}

The relevant data relating to the floor slab is divided into four categories. These four categories, shown in table 1 , contain several information respectively data about the floor slab which is needed to evaluate the Industry 4.0 use case.

Table 1: Data analysis floor slab

\begin{tabular}{|c|c|}
\hline \multicolumn{2}{|c|}{ category 1 -geometric information } \\
\hline thickness: $200 \mathrm{~mm}$ & concrete cover: $35 \mathrm{~mm}$ \\
\hline \multicolumn{2}{|c|}{ category $2-$ material } \\
\hline $\begin{array}{c}\text { reinforcement: } \mathrm{s}=150 \mathrm{~mm}, \\
\mathrm{~d}=10 \mathrm{~mm}, \mathrm{~B} 500 \mathrm{~B}\end{array}$ & concrete quality: $\mathrm{C} 30 / 37, \mathrm{XC} 2$ \\
\hline \multicolumn{2}{|c|}{ category 3 - loads } \\
\hline distributed load: $500 \mathrm{~kg} / \mathrm{m}^{2}$ & single load: $750 \mathrm{~kg} / 216 \mathrm{~cm}^{2}$ \\
\hline \multicolumn{2}{|c|}{ category $4-$ surface } \\
\hline surface treatment: smoothed & flatness: DIN 18202 table 3 / line 4 \\
\hline
\end{tabular}

\section{Data analysis of robot}

For interdisciplinary consideration the data of the used robot is analysed. For this evaluation there is a versatile, high-speed, 6-axis robot used, which can handle a payload of $50 \mathrm{~kg}$ and uses a workspace of $2.061 \mathrm{~mm}$. The given information respectively data of the manufacturer are collected and categorized in table 2.

Table 2: Data analysis robot

\begin{tabular}{|c|c|}
\hline \multicolumn{2}{|c|}{ category 1 -geometric information } \\
\hline \multicolumn{2}{|c|}{ maximum workspace: $2,061 \mathrm{~mm}$} \\
\hline \multicolumn{2}{|c|}{ category 2 - environmental conditions } \\
\hline temperature: $0-45^{\circ}$ & humidity: $20-80 \%$ \\
\hline \multicolumn{2}{|c|}{ category 3 - loads } \\
\hline dead load: $550 \mathrm{~kg}$ & ultimate load: $50 \mathrm{~kg}$ \\
\hline \multicolumn{2}{|c|}{ category 4 -maximum torque } \\
\hline axis S: $0 \mathrm{Nm}$ & axis $\mathrm{U}: 0 \mathrm{Nm}$ \\
\hline axis T: $147 \mathrm{Nm}$ & axis $\mathrm{B}: 216 \mathrm{Nm}$ \\
\hline axis L: $0 \mathrm{Nm}$ & axis R: $216 \mathrm{Nm}$ \\
\hline \multicolumn{2}{|c|}{ category $5-$ maximum speed } \\
\hline axis S: $180 \%$ sec. & axis $\mathrm{U}: 178 \%$ sec. \\
\hline axis $\mathrm{T}: 360 \%$ sec. & axis B: $250 \%$ sec. \\
\hline axis L: $178 \%$ sec. & axis R: $250 \%$ sec. \\
\hline \multicolumn{2}{|c|}{ category $6-$ maximum workspace } \\
\hline axis S: $180^{\circ}$ & axis $\mathrm{U}:+251^{\circ} /-170^{\circ}$ \\
\hline axis $\mathrm{T}: 360^{\circ}$ & axis $\mathrm{B}: 125^{\circ}$ \\
\hline axis $\mathrm{L}:+135^{\circ} /-90^{\circ}$ & axis R: $360 \%$ sec. \\
\hline \multicolumn{2}{|c|}{ category $7-$ maximum moment of inertia } \\
\hline axis $\mathrm{S}: 0 \mathrm{~kg} \mathrm{x} \mathrm{m}^{2}$ & axis $\mathrm{U}: 0 \mathrm{~kg} \mathrm{x} \mathrm{m}^{2}$ \\
\hline axis $\mathrm{T}: 11 \mathrm{~kg} \mathrm{x} \mathrm{m}^{2}$ & axis B: $28 \mathrm{~kg} \mathrm{x} \mathrm{m}^{2}$ \\
\hline axis L: $0 \mathrm{~kg} \mathrm{x} \mathrm{m}^{2}$ & axis $\mathrm{R}: 28 \mathrm{~kg} \mathrm{x} \mathrm{m}^{2}$ \\
\hline
\end{tabular}

Problems among analysing the data are the uncertainty about the exact workflows of the robot which is mostly not known during the planning on the one hand. On the other hand, the exact payload during the workflow often is not available at the planning. By considering figure 2 the six different axes of the robot can be recognized. Though there is no information about the weights of the different parts, whereby the dynamic forces caused by the movement and acceleration of the robot cannot be determined exactly. The exact workflow combined with the real used payload and the different weights of the parts are essential information for making the right decision, which fastening system is the best to use and which forces act on the robot, the floor slab and especially on the fastening systems. By not knowing the exact workflows and payload an efficient and economic use of fastening systems is impossible.

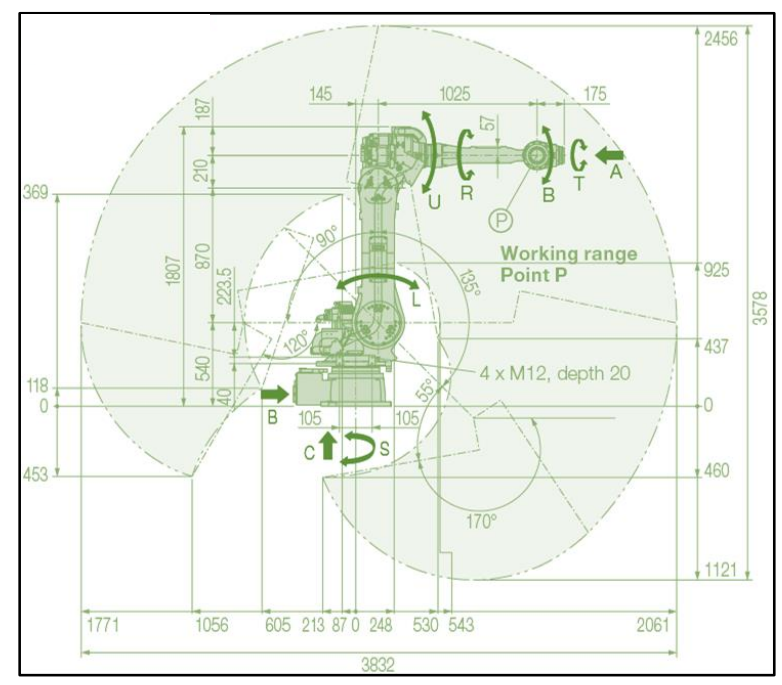

Figure 2: Working range and axes of the robot (Yaskawa, 2018)

\section{Data analysis of fastening systems}

In this step the data of the fastening system as link between the building part floor slab and the Industry 4.0 case robot is analysed. Moreover, the data of the other systems (floor slab and robot) which are influencing the dimensioning of the fastening system are identified.

As such, the BIM environment can help in avoiding conflict at the interface represented by the fastening, as for example clashes of the borehole with reinforcement, or inadequate dimensioning of the fixture plate. At the same time the data provided from both adjunct systems at the fastening, i.e. the substrate (floor slab) and the attached element (robot-including its base plate), are used as input for the fastening design. Table 1 provides the necessary concrete structural properties, while the loading can be delivered based on the information of table 2 . Here it should be noted that the loading characteristics are of particular importance for the design of fasteners and robot foundations, since they are complex dynamic loads, often in various combined directions. This 
information is vital for an efficient design against fatigue loading, and it can serve as a basis for service life prediction and maintenance (Hoepfner et al., 2018). However, it is often lost in the transfer of information from the robot programmer to the fastening designer and specifier, over various other technical and management intermediate disciplines. A solution of this problematic based on BIM integration forms part of the present case study.

The structural design of the fastening based on the load envelope discussed above, can then deliver not a single, but a multitude of appropriate fastening products for the given fixture arrangement as dictated by the 3D Building model. The final selection of the fastening can then be delivered with consideration of a second periphery of information, related to the cost, delivery and work logistics, and life-cycle management. The initially qualified elements may remain in the database to facilitate change orders. As regards life-cycle management, besides the long-term structural reliability of the fastening product, important information is the possibility of inspection and testing of the fastening element during its service life, and an appropriate decommissioning and removal. Since fastenings are construction products they are typically delivered with specifications by the manufacturer (e.g. Declaration of Performance), and an associated approval/assessment document. Once the final selection is concluded, the following information should be conveyed into the multidimensional BIM model.

Fixing-point specific:

- Product name and description

- Location

- Installation date and crew

- Installation deviations and confirmation of pretesting (as-built input)

- Maintenance intervals and expected service life

Indexed information:

- Performance specification and/or approval document (CE and ETA in Europe)

- Installation instructions

- Sub-contract and procurement details

- Project/designer's specification

- Possible alternatives (initially selected elements)

Fastenings can then be included in the BIM model at different Levels of Detail (LOD) (Mahrenholtz et al., 2017). A precise definition (LOD 300+) of the fastening as distinct individual elements is particularly necessary when the fastening element is critical to human safety, physical damage, interface conflicts, or life-cycle management issues.

Considering the undisrupted functioning of the robot as a vital part of the factory operational profits, the preselection of fastenings based on the structural calculations, and the final decision based on integrated information are showcased herein. In this context, a total number of five different fastening systems, including four bonded anchors and an undercut anchor, are considered for adapting the robot in the through-setting design and tested for the specific use of this case study. The static calculation based on the physical motion processes of the robot and the resulting dynamic loads. In this case, these were determined by a motion analysis in position and time and then calculated on the basis of dynamic motion equations and the assignment of individual masses to load functions (figure 3).

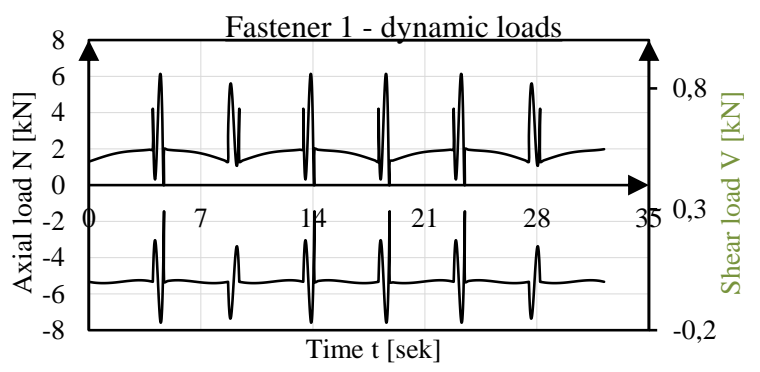

Figure 3: Load functions of the fastener 1

In comparison, this precise and sometimes elaborately determined information is often missing in practice, with the result that only conservative approaches are used and the reference to the three-dimensional position and time is completely non-existent. Above all, the process time, respective acceleration and the direction of the resulting load vector represent disproportionately high influencing factors for an adequate and reliable dimensioning of the action.

In addition to these mechanical boundary conditions, geometric axial and edge distances, concrete member and fixture thicknesses, as well as material-technical factors in the form of concrete strength classes must be considered and controlled.

\section{Data analysis of fastening systems}

As in chapter I. described all the information of the data analysis is united in one Building Information Model. For that, the geometric information of different components have to be modeled in a BIM capable CAD software. In this case study Autodesk Revit is used for the modeling step. Subsequently, the information respectively data is inserted, which is based on the components generated in the several analyses. 


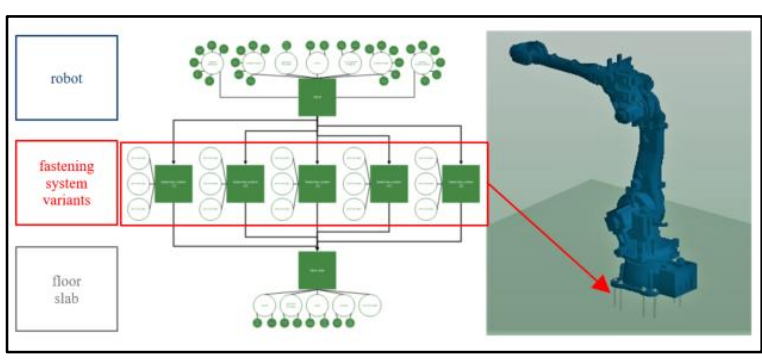

Figure 4: Data composition with BIM

For checking the whole system in terms of interfaces and dependencies afterwards the model-checking software Solibri, which is able to insert several rules for individual control options is used. In order to check the system regarding the effects of different variants of fastening systems on the parameters cost and time the calculation software system RIB iTWO is used. The software environment and dataflow are illustrated in figure 5 .

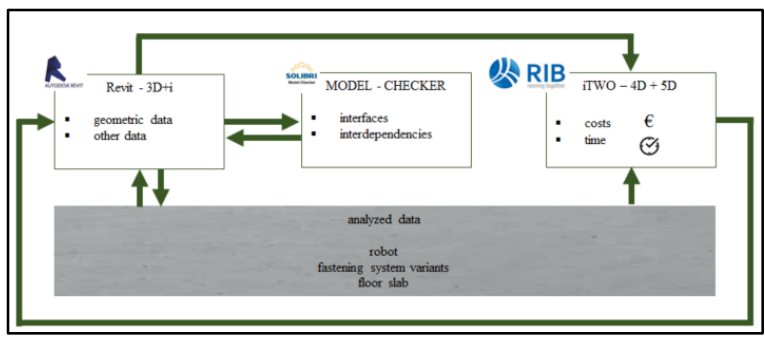

Figure 5: Software environment and dataflow (Autodesk, Solibri, 2017)

\section{Investigation of potentials with BIM}

In order to determine whether there is potential in the design of fastening systems by using the BIM-method, it is necessary to examine existing interfaces between the software applications as well as interfaces and dependencies between the building components.

\section{Interfaces and interdependencies}

After all components to be investigated, the robot, the different fastening systems and the floor slab have been created in Autodesk Revit, the combined model has to be imported into the Solibri Model checker. Therefor the IFC format (Industry Foundation Classes), which is an open standard in the building industry for the digital description of building models, is used. The IFC format can transport the geometric and semantic information through different BIM capable software environments. In this case the "IFC $2 \times 3$ Coordination View" format is used. To ensure that all the necessary information is available in the IFCfile, various configurations are required while creating the file by exporting the model from the CADsoftware.

The interfaces resulting from the assembly of the components can be checked by suitable rules in the Solibri Model Checker. Furthermore, the existing dependencies between the components (robot, fastening system, floor slab) are mainly influenced by the different usable anchors. Decisive parameters are shown in the data sheets and building control approvals of the fastening systems. In order to be able to evaluate these model-based, they are attached as information to the various components in the BIMmodel. For checking the interfaces and interdependencies in the Solibri Model checker there are rules created which consider the following parameters which are important for the dimensioning of the anchors.

- Bonding depth of the anchors and edge distance of the anchors to the floor slab

- Concrete quality

- Collision between anchors and reinforcement

- Thickness of the mounting plate

- Accessibility for using a torque wrench

- Centre distance of the anchors

The various rules are described and analyzed hereafter.

\begin{tabular}{|c|c|}
\hline 、 娄 2018-08-02_Ruleset_ICCCBE & \\
\hline$\S$ bonding depth of the anchors and edge distance of the anchors to floor slab & SOL/234/1.2 \\
\hline$\S$ concrete quality & SOL/230/1.1 \\
\hline$\S$ collision between anchors and reinforcement & SOL/1/5.0 \\
\hline$\S$ thickness of the mounting plate & SOL/234/1.2 \\
\hline$\S$ accessibility for using a torque wrench & SOL/226/1.0 \\
\hline$\S$ centre distance of the anchors & SOL/222/4.0 \\
\hline
\end{tabular}

Figure 6: Created rules for analysis

The interdependencies "bonding depth of the anchors" and "edge distance of the anchors to the floor slab" are put together in one rule. It examines the distance of the anchors to the edge and bottom edge of the floor slab. Therefore, the components and their names are used for testing. It is also necessary to define minimum and maximum distances to the edge and bottom edge of the floor slab, as shown in figure 7. It is not possible to define a variable value via an attribute with the software, but only to check static lengths, which makes it necessary to adjust the distances for each anchor variant.

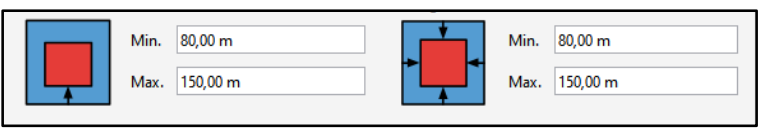

Figure 7: Definition of minimum and maximum distance

With the rule "concrete quality" a check, if the concrete quality is sufficient to use the anchor in the floor slab is possible. For this, there is a rule defined, which verifies that the given concrete quality of the floor slab is within a range of the suitable concrete quality of the anchor.

The third rule can be used to check whether there is a collision between the fastening system and the reinforcement. For this requirement, the geometric information of the selected components is used and issues an error message as soon as these components 
collide. Furthermore, the conflicting components are graphically highlighted to be able to identify them quickly, as visualized in figure 8 .

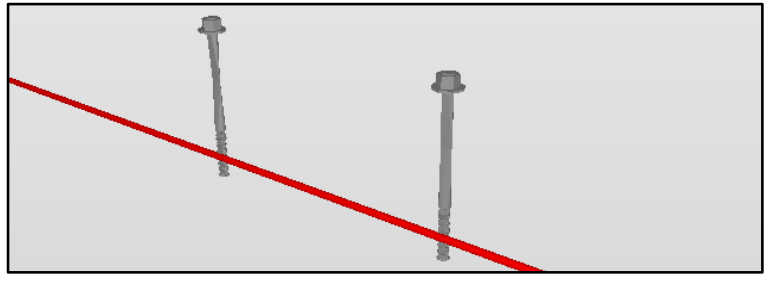

Figure 8: Detected collision between fastening systems and reinforcement

The thickness of the mounting plate is an important information for the dimensioning of the appropriate fastening system. Due to that, there was a rule created which checks if the thickness is suitable for the used fastening system. To check this requirement the robot gets the semantic information of its floor slab thickness.

The rule is used to check whether the characteristic of the thickness of the mounting plate does not exceed the limit value specified by the fastening system used. Unfortunately, it is not possible to use variable values within the rules. For this reason, it is necessary to create the requirements within the rule separately for each type of anchor fastening system. To check the accessibility to use a torque wrench for final assembly, a rule has been created that proves that there is enough space around the nut of the fastening system. As in the other rules, the several components will be addressed by their designations. In this rule, those components can be defined that are not to be taken into account. This makes sense for the component floor slab, because it is located under the nut of the fastening system but is irrelevant for the test because it does not obstruct the assembly.

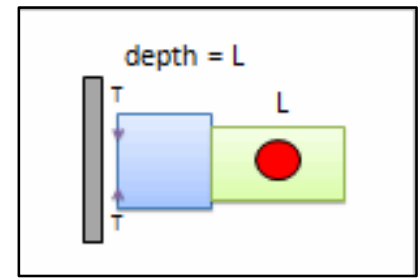

Figure 9: Determination of the free space around the nut

The last rule "centre distance anchors" checks the distance between two components in the model. To check the centre distance, there is the need to add up the diameter of the anchor to the defined distance in the rule, because otherwise only the distance from edge to edge of the two components will be tested. Beside that it is necessary to define the components which have to be checked. This can be ensured by adding the dowels as source component and target component within the rule so that it will check all components with the contained word "dowel" in its name. The created rules can be reused, reducing the time and effort for audits in other projects.

\section{Variant comparison}

Now that all variants of the fastening systems have been evaluated for their basic suitability for application in this Industry 4.0 case study, the model has been prepared for further processing in the iTWO software. For this purpose, the model was exported as a CPI-XML file from Revit for analysis in iTWO with the aim of evaluating "4D" costs and "5D" time.

After verifying the required model quality for processing in iTWO, so-called QTO-queries (quantitytake-off-queries) were developed, with which a modelbased generation of the quantities is possible. In addition, a partial service-catalogue was created for the automated preparation of a bill of quantities, which reflects in detail the various processing steps involved in the installation of a fastening system. The part performance catalog contains all service specification items with the corresponding costs in order to link them to the model and to make an evaluation of the cost differences visible.

\begin{tabular}{|c|c|c|c|c|c|}
\hline 1 & fastening systems & & & & \\
\hline 1. & Fastening system V1.0 & & & & \\
\hline \multirow[t]{2}{*}{1.1.} & fischer (bonded anchor) & & & & \\
\hline & specification & & & & \\
\hline 1.1. 10 . & hammer drilling ind. rework & 4.000 & 4.000 & St & 1.13 \\
\hline 1.1. 20. & whiff two times per anchor) & 4.000 & 4.000 & St & 0.25 \\
\hline 1.1. 30 . & brush two times per anchor) & 4.000 & 4.000 & St & 0.50 \\
\hline 1.1. 40 . & whiff two times per anchor) ind. rework & 4,000 & 4,000 & St & 0.87 \\
\hline 1.1. 50 . & injection with motar FIS HB & 4.000 & 4.000 & St & 9.50 \\
\hline 1.1. 60 . & screw in dynamic anchor FDA & 4,000 & 4.000 & St & 0.25 \\
\hline 1.1. 70 . & hardening process & 4,000 & 4.000 & St & 4.37 \\
\hline 1.1. 80 . & final assemblyt inst & 4.000 & 4.000 & St & 3.25 \\
\hline
\end{tabular}

Figure 10: Example bill of quantities fastening system iTWO

In the last step, a timetable generated in MS-Project for the different variants of the fastening systems was imported into iTWO in order to finally be able to link the individual scheduling processes with the model as well. Figure 11 shows that the decisive processes for the entire assembly time can be identified in the several hardening process (highlighted red).

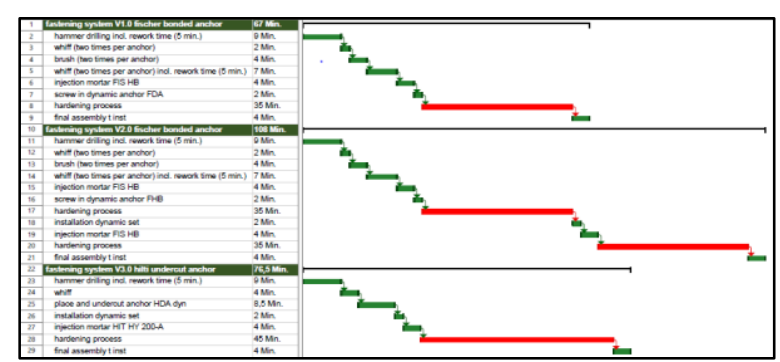

Figure 11: Example timetable fastening systems

The combination of the model with the corresponding cost and time approaches enables a comparison of variants with the use of simulation as decision support for the selection of the most suitable fastening system in iTWO. The BIM approach for semi-automatic decision support in this case study shows differences between the investigated fastening systems in terms of quality, costs and the installation time. 


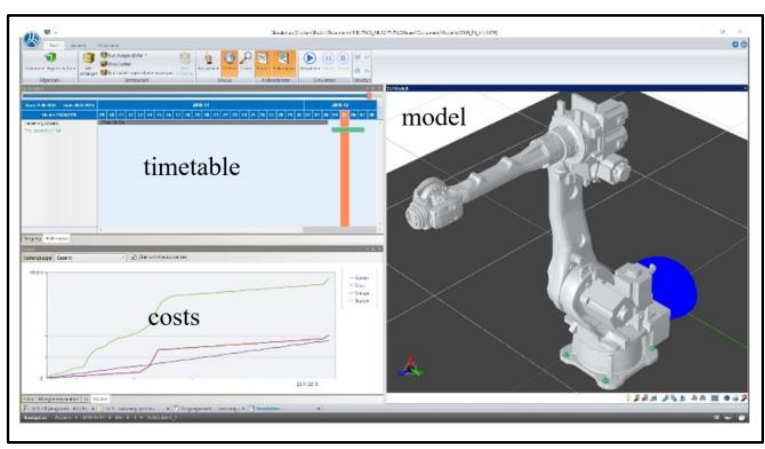

Figure 12: example simulation fastening system in iTWO

It can be assumed, similar to the use of the different rule sets in Solibri, that the generation of the QTOqueries, combination of the model with the part performance catalogs and timetables as well as the creation of these must only take place once conceptually and can subsequently be adapted to the respective use case, which reduces time and efforts in the factory adaptation planning.

\section{Evaluation matrix of possibilities}

Based on the analysis delivered above, it is possible to quantitatively assess the various solutions and perform a multi-objective optimized decision on the most appropriate system. In this case, the selection is performed based on a co-evaluation of four main criteria, namely geometrical assembly of the item fastening (3D+i), costs (4D), time (5D), and utilization factor (UF), as discussed above.

The first criterion reflects a grading against geometric collisions and project-product compatibility requirements. In particular, the following items are checked: bonding depth, concrete class, collision between anchors and reinforcement, thickness of the mounting plate, accessibility, and center distance. The decisive parameter in this comparison appears to be the embedment depth. Costs and time are evaluated per product, and with consideration of the labor cost and time required for installation; there is also a correlation between these two criteria. Finally, the design utilization factor according, indicates if the anchor's structural capacity is utilized, particularly in this case against steel failure.

The utilization factor for the relevant types of concrete failures (concrete cone failure, splitting, pull out and pry out) are calculated and verified, but not stated below, as the values is of secondary importance with a maximum utilization of $19 \%$ in this specific case study. This indicates on the one hand that the assessment is reasonably economical. Inversely, it indicates the residual safety reserves of the system. The grading for all criteria is then normalized to a 0 100 scale.

For the cost and time criteria, the normalization is performed against the fastening system with the highest value respectively. The normalization of the utilization rate is carried out in such a way, that the value 100 reflects the total load-bearing capacity utilization (LCU) of the respective fasting system and theoretically, the increase greater than 100 represents a failure. The results are provided in Table III, and they are illustrated in a spider-graph, to facilitate the decision procedure. The qualified fastening system is V 4.0, with slightly higher costs than V3.0, though with best scoring in all other criteria against all other options.

\section{Table 3: Evaluation summary}

\begin{tabular}{|c|ccc|c|}
\hline \hline $\begin{array}{c}\text { evaluation } \\
\text { fastening system }\end{array}$ & $\begin{array}{c}3 \mathrm{D}+\mathrm{i} \\
\text { grading* }\end{array}$ & $\begin{array}{c}4 \mathrm{D} \\
\text { costs** }^{* *}\end{array}$ & $\begin{array}{c}5 \mathrm{D} \\
\text { time** }\end{array}$ & $\begin{array}{c}\text { load } \\
\text { capacity } \\
\text { utilisation }\end{array}$ \\
\hline V 1.0 & 91.67 & 69.55 & 53.04 & 75.00 \\
\hline V 2.0 & 91.67 & 90.70 & 93.91 & 62.00 \\
\hline V 3.0 & 83.33 & 100.00 & 66.52 & 97.00 \\
\hline V 4.0 & 91.67 & 99.31 & 100.00 & 96.00 \\
\hline V 5.0 & 100.00 & 71.28 & 65.22 & 87.00 \\
\hline
\end{tabular}

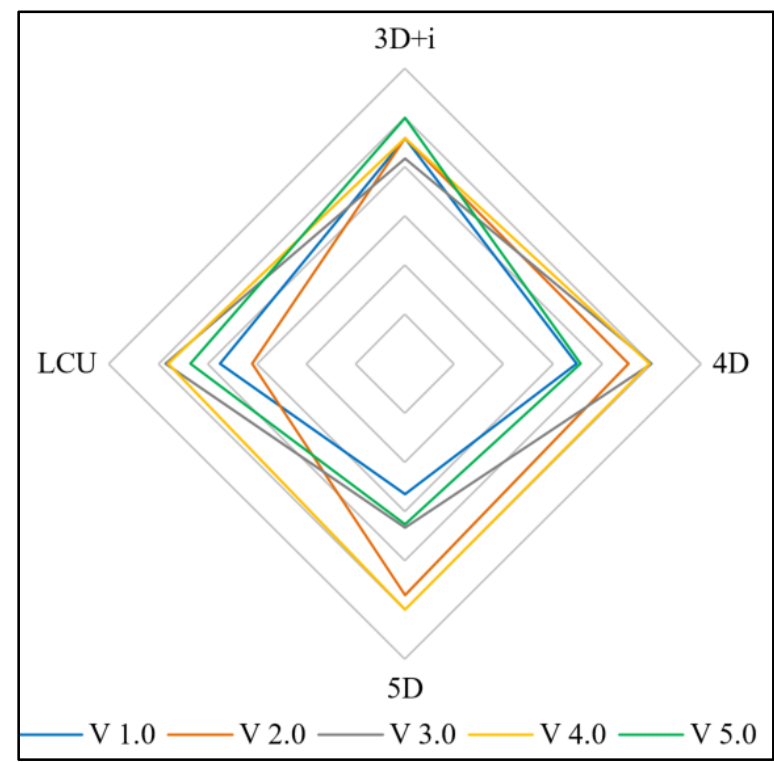

Figure 13: Evaluation summary on spider-graph as decision tool

\section{Conclusion}

Based on the study presented herein, it becomes evident that implementation of the comprehensive digital tool for the design of a fastening system in the Industry 4.0 environment is particularly efficient. Through the process proposed herein, the data input for the design is substantially richer in quantity and quality, allowing for higher precision, transparency, and thus a safer, and more economical design. Furthermore, duplex tasks are avoided since they are combined and handled simultaneously (e.g. check of anchor location and geometry against the reinforcement, the slab thickness, the mounting plate, or other project specifications). Since the database is commonly accessible by all disciplines, it serves as a 
key element in the collaboration and adaptation requirements of the work at hand. Finally, it is made evident that, including a digital data sheet (standardized e-document) with the procurement of construction products, in this case fastening systems, is of particular advantage for design and construction in the future.

\section{Outlook}

Based on this study, significant attributes of digital planning on the basis of multidimensional Building Information Models are disclosed. This requires the establishment of basic requirements in the digital documentation discussed above. At a further step, we aim to identify how different layers (from different disciplines involved) can be further combined and incorporated in the model. This is shown herein on the basis of interconnecting the structural engineer, fastening specifier and procurer, robot manufacturer, and production planner. A further endeavor is to integrate control of the installation defects risks through BIM models, including geometry and location checks of the fixture in relation to ergonomics.

\section{References}

Autodesk, Solibri (2017) Available: http://www.autodesk.de /products/revitfamily/overview, https://thebim store.com/bimproducts/solibri/solibri-model-checker.html.

Accessed: 30-Sept.-2017.

Delbruegger, T., Lenz, L., Losch, D., Roßmann, J. (2017) A Navigation Framework for Digital Twins of Factories based on Building Information Modeling. In: $22^{\text {nd }}$ International Conference of Emerging Technologies and Factory Automation 2017. Limassol, Cyprus.

Egger, M., Hausknecht, K., Liebich, T., Pryzybylo, J. (2013) BIM Leitfaden für Deutschland. Information und Ratgeber. Endbericht. In: ZukunftBAU 2013.

Gralla, M., Lenz, L. (2017) Digitalisierung im Baubetrieb - Building Information Modeling und virtuelle Zwillinge. In: Festschrift für Prof. Motzko 2017, Darmstadt, Germany.

Gralla, M., Lenz, L. (2018) Datenkomposition im Spezialtiefbau mit BIM. In: Beiträge zum RuhrGeo Tag 2018 Innovationen im Spezialtiefbau und in der Umweltgeotechnik 2018. Bochum, Germany.

Hoepfner, M., Spyridis, P. (2018) Early damage detection of fastening systems in concrete under dynamic loading - model details and health monitoring framework. In: IALCCE 2018 The
Sixth International Symposium on Life-Cycle Civil Engineering 2018. Ghent, Belgium.

Mahrenholtz, C., Neumann, D., Spijkers, G. (2017) Connected with BIM - a review of BIM for construction products like anchor channels. In: Proceedings, 3rd International Symposium on Connections between Steel and Concrete 2017. Stuttgart, Germany.

Yaskawa Europe $\quad \mathrm{GmbH} \quad$ (2018) Available:https://www.yaskawa.eu.com/index.php ?eID=dumpFile $\& \mathrm{t}=\mathrm{f} \& \mathrm{f}=15406 \&$ token $=\mathrm{a} 1 \mathrm{~d} 93934$ 272f624864ac2210c3ac32291a8326a6. Accessed: 11-July-2 